\title{
DESENVOLVIMENTO DE PROCESSOS FÍSICO-QUÍMICOS PARA AUMENTAR A EFICIÊNCIA DA COMBUSTÃO DA VINHAÇA, UTILIZANDO RESÍDUOS DO SETOR SUCROENERGÉTICO.
}

\author{
P. Sica ${ }^{1}$, A. S. Baptista ${ }^{2}$, F. Tonoli ${ }^{3}$, H. Beltrame ${ }^{4}$ \\ 1;3;4 Aluno de Graduação da Escola Superior de Agricultura "Luiz de Queiroz"- \\ Universidade de São Paulo (USP) - Departamento de Agroindústria, Alimentos e Nutrição \\ (LAN) \\ ${ }^{2}$ Professor Doutor da Escola Superior de Agricultura "Luiz de Queiroz" - Universidade de \\ São Paulo (USP) - Departamento de Agroindústria, Alimentos e Nutrição (LAN)
}

E-mail para contato: pietros0394@gmail.com

\begin{abstract}
RESUMO - No processo de obtenção do etanol ocorre a geração de vários resíduos, dentre eles, o principal é a vinhaça. Para da cada litro de etanol produzido são gerados de 10 a $18 \mathrm{~L}$ de vinhaça. Este resíduo apresenta alto poder poluente. Em função disso, a CETESB, através da Norma 4.231 estabelece a necessidade de um manejo racional desse resíduo. Com isso surgiu a necessidade de novas alternativas para a gestão desse recurso, sendo que a concentração da vinhaça é uma delas. Por isso, o objetivo deste projeto é analisar a capacidade da palha deixada no campo como coadjuvante de agentes floculantes para a concentração da fração sólida da vinhaça. Os tratamentos foram realizados utilizando palha, em diferentes granulometrias e concentrações, e agentes coagulantes (Sulfato Férrico e Cloreto Férrico). A capacidade de remoção de materiais suspensos pelos diferentes tratamentos foi avaliada pela análise da turbidez. O tratamento com palha, em granulometria $<0,3 \mathrm{~mm}$ e concentração de $0,25 \%$, combinado com 400 ppm de Sulfato Férrico foi aquele mais se destacou, apresentando a redução da turbidez em 57,96\%. Conclui-se, que a palha apresenta potencial de ser utilizada como coadjuvante de tecnologia para auxiliar da remoção de colóides suspensos e dispersos na vinhaça, quando se utiliza processos centrífugos para eliminar materiais dispersos nesse resíduo. Contudo, ainda há necessidade de estudos mais detalhados para que esse processo seja otimizado.
\end{abstract}

\section{INTRODUÇÃO:}

Desde o período colonial, a cana-de-açúcar é uma das culturas mais relevantes da economia brasileira. A partir do século XIX, com a Primeira Revolução Industrial, a demanda por energia é crescente, sendo que, nas últimas décadas, aumentou a necessidade por energias provindas de fontes renováveis. No Brasil, de acordo com o Ministério de Minas e Energia, no ano de 2013 produtos provindos da cana-de-açúcar foram responsáveis por 15,4\% da Matriz Energética Brasileira, ficando atrás apenas do Petróleo e seus derivados $(39,2 \%)$. No setor Sucroenergético a queima do bagaço da cana e o Etanol têm grande destaque como fontes de energia renovável. Entretanto, na cadeia produtiva do etanol são gerados uma série de resíduos, dentre eles a palha da cana, que permanece no campo após a 
colheita e a vinhaça, líquido com baixo $\mathrm{pH}$ e alta demanda química de oxigênio.Por esses motivos, o objetivo desse trabalho foi utilizar a palha remanescente no campo após a colheita da cana-de-açúcar como coadjuvante de tecnologia para auxiliar agantes floculantes (Sulfato Férrico e Cloreto Férrico) no processo de concentração da vinhaça por centrifugação.

\subsection{Palha do solo:}

Antes da lei $\mathrm{n}^{\circ}$ 11.241/2002 do estado de São Paulo, era permitida a queima da cana na ocasião da pré-colheita. A partir de 2002, a queima vem sendo proibida gradativamente, devido ao impacto negativo que a fumaça resultante da combustão desse material ao meio ambiente, tendo sua proibição efetiva prevista para o ano de 2014. Com isso, há a necessidade de alternativas para transformar esse resíduo em um material de interesse econômico, como manutenção no campo para um sistema de plantio direto e queima nas caldeiras da usina, visando a geração de energia elétrica.

\subsection{Vinhaça:}

A vinhaça é um resíduo gerado no processo de obtenção do etanol com poder poluente cem vezes maior que o do esgoto doméstico, devido à sua riqueza em matéria orgânica, baixo $\mathrm{pH}$, elevada corrosividade e altos índices de demanda química de oxigênio (DQO) (Freire e Cortez, 2000). De acordo com Rosseto (1987), para cada litro de etanol produzido são gerados entre 10 e $18 \mathrm{~L}$ de vinhaça. A partir do ano de 2006, com a Instrução Normativa N.4.231 da CETESB, que estabelece uma série de condições para a aplicação desse resíduo, vem aumentando a necessidade de novos estudos em relação ao gerenciamento da vinhaça. Esta, atualmente, tem que ser transportada para locais cada vez mais longes da usina, aumentando o custo de logística. De acordo com Camhi (1979), a concentração desse resíduo é uma boa alternativa para seu manejo. Segundo Faria (2011), a concentração da vinhaça, além de poder ser uma fonte de água para a indústria sucroenergética, diminui o volume de vinhaça a ser transportado para o campo, reduzindo custos de transporte em caminhões-tanques para a lavoura com fins de fertilização.

\section{Objetivos:}

Os objetivos desse trabalho foram:

- utilizar a palha remanescente da colheita no campo como coadjuvante de tecnologia auxiliar de agentes floculantes no processo de concentração da vinhaça;

-determinar a concentração ideal e a melhor granulometria da palha para a concentração da vinhaça;

-determinar a concentração ideal de agentes floculantes na concentração da vinhaça.

\section{Materiais e Métodos}

Os tratamentos foram realizados em quatro repetições, utilizando palha com granulometria menor que $0,3 \mathrm{~mm}$ e nas concentrações de $0 \% ; 0,1 \% ; 0,25 \%$, juntamente com agentes floculantes (Sulfato Férrico e Cloreto Férrico) nas concentrações de 0; 50; 100; 200; 300; 400 e 500ppm, conforme pode ser visto nas tabelas 1, 2 e 3. 
Tabela1: Tratamentos com Sulfato Férrico.

\begin{tabular}{|l|r|r|}
\hline & \multicolumn{2}{|c|}{ Sulfato Férrico: } \\
\hline & $\begin{array}{l}\text { Palha } \\
\text { Tratamento: }\end{array}$ & $\begin{array}{l}\text { Reagente } \\
\text { (ppm) }\end{array}$ \\
\hline S R1 P0 & 0 & 100 \\
\hline S R2 P0 & 0 & 200 \\
\hline S R3 P0 & 0 & 50 \\
\hline S R1 P1 & 0,1 & 100 \\
\hline S R2 P1 & 0,1 & 200 \\
\hline S R3 P1 & 0,1 & 300 \\
\hline S R4 P1 & 0,1 & 400 \\
\hline S R5 P1 & 0,1 & 500 \\
\hline S R6 P1 & 0,1 & 50 \\
\hline S R1 P2 & 0,25 & 100 \\
\hline S R2 P2 & 0,25 & 200 \\
\hline S R3 P2 & 0,25 & 300 \\
\hline S R4 P2 & 0,25 & 400 \\
\hline S R5 P2 & 0,25 & 500 \\
\hline S R6 P2 & 0,25 & \\
\hline
\end{tabular}

Tabela 2: Tratamentos com Cloreto Férrico

\begin{tabular}{|l|r|r|}
\hline \multicolumn{3}{|c|}{ Cloreto Férrico: } \\
\hline & \multicolumn{2}{|c|}{ Descrição: } \\
\hline Tratamento: & $\begin{array}{l}\text { Palha } \\
\text { (\%) }\end{array}$ & $\begin{array}{l}\text { Reagente } \\
\text { (ppm) }\end{array}$ \\
\hline C R1 P0 & 0 & 50 \\
\hline C R2 P0 & 0 & 100 \\
\hline C R3 P0 & 0 & 200 \\
\hline C R1 P1 & 0,1 & 50 \\
\hline C R2 P1 & 0,1 & 100 \\
\hline C R3 P1 & 0,1 & 200 \\
\hline C R4 P1 & 0,1 & 300 \\
\hline C R5 P1 & 0,1 & 400 \\
\hline C R6 P1 & 0,1 & 500 \\
\hline C R1 P2 & 0,25 & 50 \\
\hline C R2 P2 & 0,25 & 100 \\
\hline C R3 P2 & 0,25 & 200 \\
\hline C R4 P2 & 0,25 & 300 \\
\hline C R5 P2 & 0,25 & 400 \\
\hline C R6 P2 & 0,25 & 500 \\
\hline
\end{tabular}

Tabela 3: Tratamentos sem reagentes

\begin{tabular}{|l|r|l|}
\cline { 2 - 3 } \multicolumn{1}{c|}{} & \multicolumn{2}{c|}{ Descrição: } \\
\hline Tratamento: & $\begin{array}{l}\text { Palha } \\
\text { (\%) }\end{array}$ & $\begin{array}{l}\text { Reagente } \\
\text { (ppm) }\end{array}$ \\
\hline R0 & 0 & \\
P0 (controle) & 0,1 & 0 \\
\hline R0 P1 & 0,25 & 0 \\
\hline R0 P2 & & 0 \\
\hline
\end{tabular}

Tabela 3: Tratamentos sem reagentes

A palha foi homogeneizada com a vinhaça com ajuda de um liquidificador industrial e posteriormente centrifugadas a $5000 \mathrm{rpm}$ por 5 minutos em Tubos de Falcon de $50 \mathrm{~mL}$.

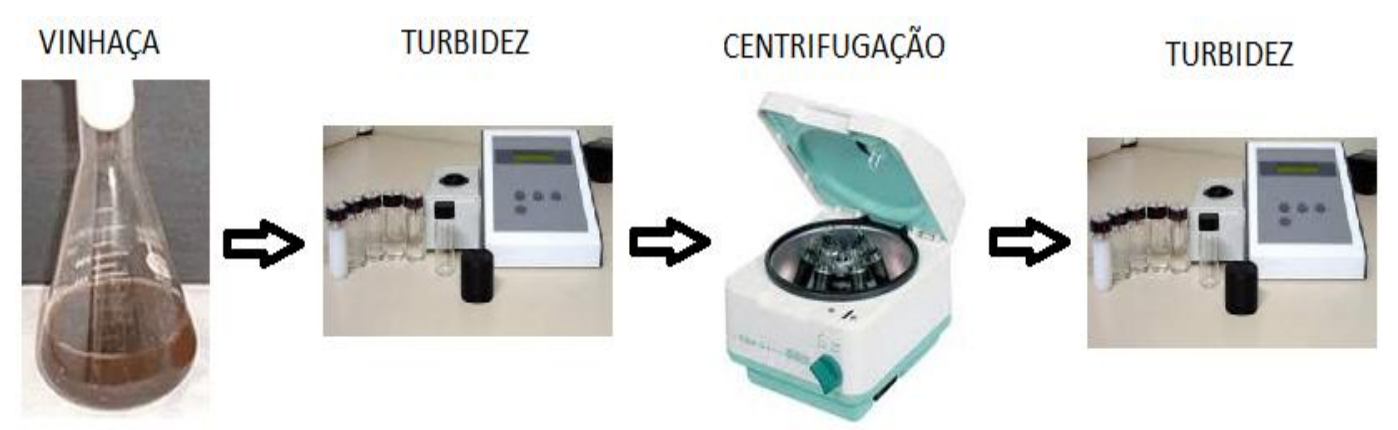

Figura 1 - Esquema do método empregado no projeto.

\section{Resultados e Discussão:}


Como pode ser visto na Tabela 4, a palha mostrou potencial como coadjuvante de agentes floculantes no processo de concentração da vinhaça por centrifugação. A palha com granulometria menor que $0,3 \mathrm{~mm}$ em concentração de $0,25 \%$ junto com Sulfato Férrico a 400 ppm (S R5 P2) foi o tratamento que mostrou melhor desempenho, reduzindo a turbidez em $57,96 \%$ de uma vinhaça com turbidez inicial 936 NTU, enquanto o controle negativo reduziu em apenas $42,58 \%$ a turbidez final.

Tabela 4 - Resultados da leitura de tubidimetria nas amostras analisadas

\begin{tabular}{|l|r|}
\hline Tratamento: & Turbidez Final (NTU): \\
\hline R0 P0 (controle) & $\mathbf{5 3 7 , 5} \pm \mathbf{7 , 7 2}$ \\
\hline R0 P1 & $618,25 \pm 18,63$ \\
\hline R0 P2 & $524,75 \pm 17,33$ \\
\hline S R1 P0 & $497,5 \pm 3,7$ \\
\hline S R2 P0 & $471,25 \pm 13,45$ \\
\hline S R3 P0 & $441,5 \pm 5,8$ \\
\hline S R1 P1 & $493,25 \pm 23,77$ \\
\hline S R2 P1 & $457,5 \pm 10,79$ \\
\hline S R3 P1 & $465,75 \pm 7,37$ \\
\hline S R1 P2 & $492,75 \pm 20,19$ \\
\hline S R2 P2 & $486,5 \pm 8,66$ \\
\hline S R3 P2 & $454,25 \pm 10,5$ \\
\hline S R4 P2 & $440 \pm 8,52$ \\
\hline S R5 P2 & $\mathbf{3 9 3 , 5} \pm 5,92$ \\
\hline S R6 P2 & $413,25 \pm 5,38$ \\
\hline C R1 P0 & $535 \pm 9,38$ \\
\hline C R2 P0 & $465,5 \pm 4,20$ \\
\hline C R3 P0 & $440,5 \pm 8,18$ \\
\hline C R1 P1 & $530,5 \pm 17,69$ \\
\hline C R2 P1 & $421 \pm 11,34$ \\
\hline C R3 P1 & $447,5 \pm 5,92$ \\
\hline C R1 P2 & $510 \pm 18,22$ \\
\hline C R2 P2 & $461,25 \pm 9,03$ \\
\hline C R3 P2 & \\
\hline C R4 P2 & $474 \pm 14,65$ \\
\hline C R5 P2 & \\
\hline C R6 P2 & 19,09 \\
\hline & 455 \\
\hline
\end{tabular}

\section{CONCLUSÃO}

A palha remanescente no campo apresenta potencial como coadjuvante de tecnologia para auxiliar agentes floculantes da vinhaça. Contudo, ainda há necessidade de estudos mais detalhados para que esse processo seja otimizado. 


\section{REFERÊNCIAS}

FARIA, A. A. A. Concentração da Vinhaça e Reaproveitamento da Água - IV Semana de Tecnologia do Curso de Biocombustíveis da Faculdade de Tecnologia de Jaboticabal, 2011

FREIRE e CORTEZ (2000), Uso de vinhaça e impactos nas propriedades do solo e lençol freático. Disponível em http://www.scielo.br/pdf/rbeaa/v11n1/v11n1a14.pdf Acesso em 22/11/2013.

GOVERNO DO ESTADO DE SÃO PAULO: $\underline{\text { http://governo- }}$ sp.jusbrasil.com.br/legislacao/129474/lei-11241-02 acesso em 12 de dezembro de 2013

MINISTÉRIO DE MINAS E ENERGIA (MME)

https://ben.epe.gov.br/BENRelatorioFinal2013.aspx, acesso em 6 de março de 2014

ROSSETO, A. J. Utilização agronômica dos subprodutos e resíduos da indústria açucareira e alcooleira. In: Paranhos, S.B. (ed.). Cana-de-açúcar: cultivo e utilização. Campinas: Fundação Cargill, 1987, v.2, p.435-504. 